\section{Commentary: Another iteration of cell-based therapy for acute ischemia-reperfusion injury, this time in the spine}

\author{
Jeremy L. Herrmann, MD
}

Spinal cord injury is among the most feared complications of surgery for descending thoracic aortic pathology due to its devastating consequences and the mixed effectiveness of pharmacologic and lumbar drainage preventative and rescue therapies. Cell-based regenerative therapies (eg, stem cells or mesenchymal stromal cells [MSCs]) have received undulating attention over the past 15 years for the potential ability to protect against, or facilitate recovery from, ischemia-reperfusion injury in a variety of tissues. The literature is robust, with animal model-based studies while the translational leap to the clinical stage has been very limited and inconsistent. ${ }^{1}$ This is largely due to the many confounding anatomical and physiological factors between bench and bedside. ${ }^{2}$

Cell-based therapies offer putative protective mechanisms of paracrine release of proangiogenic, anti-inflammatory, and antiapoptotic growth factors and cytokines. It is through these mechanisms that the authors speculate using the present observational data that human bone-marrow-derived MSCs may protect spinal cord motor neurons during episodes of acute ischemia and reperfusion in mice. ${ }^{3}$ Their technically elegant surgical model involved inducing spinal cord ischemia at normothermia by crossclamping the aortic arch in 2 locations. Commercially available male human bone-marrow-derived MSCs (or control solution) were injected in standard doses into the tail veins of female mice 2 hours after reperfusion. This sex selection was intentional to allow for assaying graft cell localization and retention with chromosomal detection.

\footnotetext{
From the Indiana University School of Medicine, Indianapolis, Ind; and Riley Children's Health at Indiana University Health, Indianapolis, Ind.

Disclosures: The author reported no conflicts of interest.

The Journal policy requires editors and reviewers to disclose conflicts of interest and to decline handling or reviewing manuscripts for which they may have a conflict of interest. The editors and reviewers of this article have no conflicts of interest.

Received for publication June 28, 2021; revisions received June 28, 2021; accepted for publication June 29, 2021; available ahead of print July 19, 2021

Address for reprints: Jeremy L. Herrmann, MD, Indiana University School of Medicine, 545 Barnhill Dr, Emerson 215, Indianapolis, IN 46202 (E-mail: jlherrma@iupui.edu).

JTCVS Open 2021;7:41-2

2666-2736

Copyright (C) 2021 The Author(s). Published by Elsevier Inc. on behalf of The American Association for Thoracic Surgery. This is an open access article under the CC BY-NC-ND license (http://creativecommons.org/licenses/by-nc-nd/4.0/).

https://doi.org/10.1016/j.xjon.2021.06.021
}

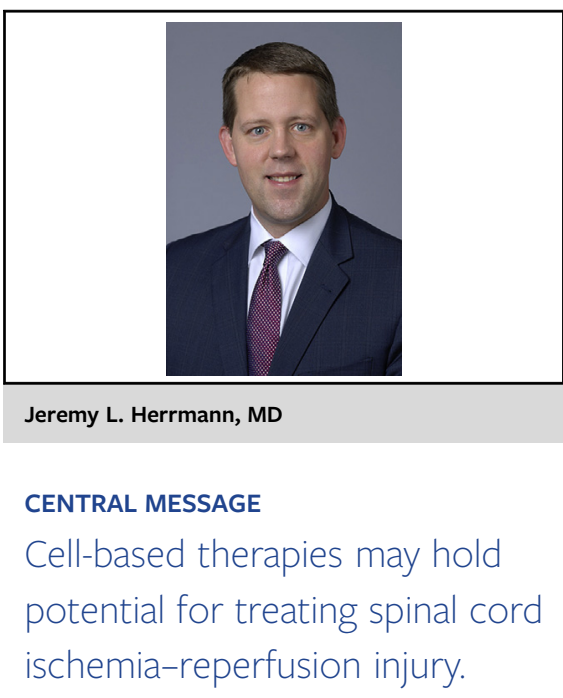

Hind limb function appeared to recover earlier in the MSCs group (as early as 8 hours after reperfusion) as well as recover to baseline or near-baseline up to 28 days after surgery. Histologically, there appeared to be more motor neuron preservation in the lumbar spinal cord, and donor MSCs were identified in areas of spinal cord, lung, spleen, and kidney. Reverse transcription polymerase chain reaction analysis of mRNA expression in spinal cord tissue showed a more anti-inflammatory, proangiogenic profile in the MSCs group. The authors conclude that MSC administration did not affect overall survival but could reduce the degree of spinal cord injury and paraplegia after temporary interruption of aortic flow at normothermia.

There are several important limitations of this study, most of which are acknowledged in the article. The sample sizes are very small, and the mortality rate in both groups appeared to be very high (although typical for this model). Because cardiovascular outcomes and MSCs function may differ between men and female women, it would have been helpful to account for such variations using opposite combinations of groups. ${ }^{4}$ Finally, these observations are purely descriptive because specific mechanisms were not evaluated.

However, the main strength of this study is the novel application of MSCs for treating acute spinal cord ischemia-reperfusion injury, whereas the vast majority of prior work has focused on traumatic injury. ${ }^{5-7}$ The potential of this work to directly assess benefits of cellbased therapy for acute spinal cord ischemia-reperfusion injury in a model that mimics aortic surgery should capture the attention of cardiovascular surgeons. Unfortunately, as with many other small animal, basic science models, we are left with a question: What is next? 


\section{References}

1. Trindade F, Leite-Moreira A, Ferreira-Martins J, Ferreira R, Falcao-Pires Ines, Vitorino R. Towards the standardization of stem cell therapy studies for ischemic heart diseases: bridging the gap between animal models and the clinical setting. Int J Cardiol. 2017;228:465-80.

2. Abarbanell AM, Herrmann JL, Weil BR, Wang Y, Tan J, Moberly SP, et al. Animal models of myocardial and vascular injury. J Surg Res. 2010;162: 239-49.

3. Nakai H, Fujita Y, Masuda S, Komatsu M, Tani A, Okita Y, et al. Intravenous injection of adult human bone marrow mesenchymal stromal cells attenuates spinal cord ischemia/reperfusion injury in a murine aortic arch cross-clamping model. J Thorac Cardiovasc Surg Open. 2021;7:23-40.
4. Crisostomo PR, Markel TA, Wang W, Lahm T, Lillemoe KD, Meldrum DR. In the adult mesenchymal stem cell population, source gender is a biologically relevant aspect of protective power. Surgery. 2007;142:215-21.

5. Lindsay SL, Barnett SC. Therapeutic potential of niche-specific mesenchymal stromal cells for spinal cord injury repair. Cells. 2021;10:901-19.

6. Gyongyosi M, Wojakowski W, Lemarchand P, Lunde K, Tendera M, Bartunek J, et al. Meta-analysis of cell-based CaRdiac studies (ACCRUE) in patients with acute myocardial infarction based on individual patient data. Circ Res. 2015;116:1346-60.

7. Wollert KC, Meyer GP, Muller-Ehmsen J, Tschöpe C, Bonarjee V, Larsen AI, et al. Intracoronary autologous bone marrow cell transfer after myocardial infarction: the BOOST-2 randomized placebo-controlled clinical trial. Eur Heart J. 2017; 38:2936-43. 